\title{
Development and Validation of the Japanese Version of a Job Stressor Scale for Triage Nurses in Emergency Departments
}

\author{
Nojima Keisuke1, Takamizawa Emiko², Hatamochi Chieko ${ }^{3}$ \\ ${ }^{1}$ Faculty of Nursing, Kyoto Tachibana University, Kyoto, Japan \\ ${ }^{2}$ Department of Nursing, Kansai University of International Studies, Hyogo, Japan \\ ${ }^{3}$ Graduate School of Nursing, Osaka Prefecture University, Osaka, Japan \\ Email:nojima@tachibana-u.ac.jp,e-takamizawa@kuins.ac.jp,chiekos@nursing.osakafu-u.ac.jp
}

How to cite this paper: Keisuke, N., Emiko, T. and Chieko, H. (2021) Development and Validation of the Japanese Version of a Job Stressor Scale for Triage Nurses in Emergency Departments. Open Journal of Nursing, 11, 75-88.

https://doi.org/10.4236/ojn.2021.112008

Received: January 5, 2021

Accepted: February 22, 2021

Published: February 25, 2021

Copyright $\odot 2021$ by author(s) and Scientific Research Publishing Inc. This work is licensed under the Creative Commons Attribution International License (CC BY 4.0).

http://creativecommons.org/licenses/by/4.0/

\begin{abstract}
Background: With an increasing number of patients who visit emergency outpatient units, a shortage of physicians and nurses in emergency units has become an issue in Japan. Triage nurses who interview patients and their families before medical examinations feel stressed to determine the triage level in a limited time, necessitating the measures to alleviate stressors. Objective: To develop a triage nurse job stressor scale (TNJSS) for Japanese triage nurses in emergency outpatient units and to verify the reliability and validity of this scale. Methods: Anonymous, self-administered questionnaires were sent to nursing directors of 180 emergency and critical care centers randomly selected from 251 centers throughout Japan, requesting to distribute the questionnaire to nurses. Results: Based on the responses obtained from 363 nurses, the construct validity, internal consistency, and criterion-related validity were verified. A factor analysis of 44 items yielded five factors: "Lack of triage ability", "Busy triage work", "Patients without understanding of explanations", "Complaints from patients waiting for treatment", and "Lack of support to improve triage ability". Cronbach's $\alpha$ was 0.93 for the full scale and significant correlations were observed between the nurses' stressor scores and scores for the Stress Response Scale-18 $(r=0.409 ; p<0.01)$ and for the Nursing Job Stressor Scale $(r=0.410 ; p<0.01)$. Conclusions: The TNJSS with a five-factor structure containing 44 items was determined to be a reliable and valid tool for evaluating Japanese triage nurse job stressors. The findings suggest the necessity to continuously educate and support triage nurses.
\end{abstract}

\section{Keywords}

Triage, Triage Nurse, Stressor, Stressor Scale, Emergency Departments 


\section{Introduction}

Triage nursing in the emergency department is one of the most stressful jobs among medical occupations, and burnout rates among emergency nursing professionals are generally high [1] [2] [3] [4] [5]. The triage nurse role was established to give a priority rating that determines the urgency with which patients are seen. The significance of triage nursing lies in the preferential consideration of patients in poor condition, effective utilization of health resources, patient reevaluation by utilizing triage classification, improvement of patient service and increases in patient satisfaction, all leading to improvements in the quality of medical care [6] [7] [8] [9] [10]. In Japan, based on the unique social environment characterized by an increasing number of patients who visit emergency outpatient units and a shortage of physicians and nurses in emergency units, the number of hospitals where triage nurses are employed has increased.

Nurses engaged in emergency care suffer from stress caused by coping with the extreme state associated with a patient's life and death [11]. In particular, triage nurses have to interview the patient before a medical examination is conducted by a physician and therefore are the first to respond to patients and their families. They are also painfully aware of their pressure to determine the triage level in a limited time. A recent study showed that there are specific stressors associated with triage nurses [12]. Further, it was reported that the quality of nursing may decrease when nurses suffer excessively from stress and cannot maintain their mental health [13]. Triage nurses are at risk of exhaustion caused by excessive stress, leading to impaired judgment or poor quality of nursing services provided to patients and their families. Thus, there is growing concern that triage nurses cannot preserve the lives of emergency patients, and therefore measures to identify and combat job stressors of triage nurses need to be taken.

Although various tools to measure the job stressors of specific groups of nursing professionals have been developed [14]-[19], a job stressor scale for triage nurses is lacking. In previous studies on nursing, the nursing job stressor scale (NJSS) developed by Higashiguchi [18] was commonly used. However, this scale includes some items that do not apply to triage nurses, while it lacks items applicable for determining the specific stressors typically experienced by triage nurses. The purpose of the present study was therefore to develop a triage nurse job stressor scale (TNJSS) applicable to Japanese triage nurses working in emergency outpatient units and to verify the reliability and validity of this scale.

\section{Methods}

Previously, the author undertook a pilot study by conducting semi-structured interviews with 15 emergency department nurses. The length of the interviews was about 30 minutes per nurse, and the interviews were recorded on a digital voice recorder, with the permission of the participating nurses. In the interviews, the author used an interview guide which was originally created based on pre- 
vious studies [10] [13] [17] [20] [21] [22], and asked the nurses to talk about personal demographics and specific episodes they felt stressed by. Content analysis yielded the following four main stressor categories related to the triage work: dealing with life-threatening states of patients, communication with patients and their families, difficulties conducting triage, and insufficient triage abilities. Several subcategories were also identified for each of the 4 main categories [12]. Based on these findings, a draft scale was prepared by the same author. Then, the face validity of the draft was examined by an expert group consisting of nursing researchers who were familiar with emergency care and nurses with approximately ten years of clinical experience, who were engaged in emergency triage. As a result, a total of 87 items for the TNJSS were chosen by organizing similar question items, examining the consistency between the items and the relevant concepts, and revising the wording accordingly.

\subsection{Study Participants}

Participants were 363 nurses who work in an emergency outpatient unit in emergency and critical care centers throughout Japan. Exclusion criteria are for emergency and critical care centers where nurses do not perform triage in outpatient units.

\subsection{Data Collection}

Data were collected between September 2015 and January 2016. Of 251 emergency and critical care centers throughout Japan, 180 centers were randomly selected using a computer software. Anonymous, self-administered questionnaires were sent by mail to the director of nursing of each of these centers asking to distribute the questionnaire to the individual nurses. The questionnaire was made up of 4 parts. The first part contained the 87 statements of the TNJSS on the left side and a choice of 5 answers (5-point rating scale) on top of the right side. The available answers were: "I strongly agree" (5 points), "I agree" (4 points), "I neither agree nor disagree" (3 points), "I disagree" (2 points), and "I strongly disagree" (1 point). For each statement, participants were instructed to circle the point on the scale which responded to his/her level of agreement. The second part was comprised of the Stress Response Scale-18 (SRS-18) [23] (18 items, 4-point rating scale) and the third part of the NJSS (33 items, 4-point rating scale). Finally, the fourth part contained questions related to participant demographics. Participants were instructed to return the completed questionnaire by mail within an indicated time frame. Returning the questionnaire was regarded as consent to the participation.

\subsection{Data Analysis}

\subsubsection{Item Analysis}

Descriptive statistics for the question items were tabulated. The skewness and kurtosis were checked and item-remainder correlations were also determined. 


\subsubsection{Construct Validity}

Exploratory factor analysis was done according to the attenuation amount of an eigenvalue in the initial solution, with promax rotation. Confirmatory factor analysis was done by known-groups analysis. For known-groups analysis, hypotheses were developed by referring to previous studies on emergency nurses' stressors. In particular, using the NJSS, Kikuchi et al. conducted a factual survey of the stress experienced by nurses working in outpatient units [20]. Their results revealed that nurses with less than two years' experience in an outpatient unit showed higher stressor scores than did nurses with two years or more. Manabe et al. performed a study on job stressors and stress responses in inexperienced nurses during their first three years of work and found that the burden related to clinical nursing competence was a major stressor in their first year and that improvement in this area should be a top priority [21]. Furthermore, Maki et al. performed a questionnaire survey with 76 nurses engaged in a tertiary care facility to determine their actual situation regarding traumatic stress and mental health [24]. According to their results, the post-traumatic stress disorder (PTSD) high-risk group had few years of experience in an emergency department, little awareness of receiving appraisal support, and poor mental health.

The above findings indicate an association between years of experience as a nurse and stressors, even in emergency nurses, especially for nurses with few years of experience in emergency care; that nurses experience a significant state of mental fatigue as well as many stressors; and were likely to be at high risk of stress responses such as PTSD. In addition, there is a report that many institutions require triage nurses to have three years or more of nursing experience [22]. Nurses with less than three years' experience are deemed insufficient as a triage nurse. It may be difficult for nurses with less than three years of emergency nursing experience to perform triage and it is inferred that they are prone to suffer from stressors.

Thus, in this study, two hypotheses were examined. Hypothesis 1 states that "nurses with less than three years' emergency nursing experience would show higher stressor scores than nurses with three years or more of experience" and Hypothesis 2 maintains that "nurses with less than one year of triage nursing experience would show higher stressor scores than nurses with one year or more of experience." These hypotheses were examined statistically using the Mann-Whitney U test.

\subsubsection{Study Participants}

Cronbach's $\alpha$ coefficients of reliability were calculated.

\subsubsection{Criterion-Related Validity}

The SRS-18 and the NJSS were used to investigate criterion-related validity. A correlation analysis of the TNJSS with the SRS-18 and the NJSS was performed separately. The data were analyzed using IBM SPSS (Ver 0.20 for Windows).

\subsection{Ethical Considerations}

A letter accompanying the questionnaire explained the purpose and the signi- 
ficance of the study, privacy protection, as well as consent to participation and publication of the results. In the letter, it was also made clear that participation is voluntary and that answering the questionnaire could be cancelled at any time if the participant felt uncomfortable while responding to any of the questions. Receipt of the completed questionnaire indicated each participant's consent to participate in the study.

The anonymous questionnaire was prepared in a way that allowed the participants to return it by mail at their own discretion so that the representatives of the medical institutions would be unaware of the nurses' participation in the study. Similarly, the authors were also unaware of which medical institution(s) the returned questionnaires came from. This study was conducted after obtaining the approval of the ethical committee of the O University (approval number: 26-36, approved on September 25, 2014).

\section{Results}

\subsection{Characteristics of Study Participants}

Out of 900 nurses, 385 nurses (response rate of 42.8\%) returned the questionnaire. After exclusion of 22 nurses who provided incomplete responses, the data of 363 nurses (valid response rate of 40.3\%) were included in the analysis. Table 1 shows the participants' characteristics (Table 1).

\subsection{Item Analysis}

Descriptive statistics were calculated for the 87 items of the TNJSS. The normality of the stressor scores was confirmed by examining the skewness and kurtosis; one biased item was deleted. Then, two items that exhibited a ceiling effect $([$ mean $+S D]>5)$ were also deleted. There was no item for which a floor effect $([$ mean $+\mathrm{SD}]<1)$ was indicated. For the results of the item-remainder correlation analysis, Pearson correlation coefficients of $0.56-0.11$ were obtained. Four items with a correlation coefficient of 0.25 or less were deleted. A total of 80 items went into further analysis.

\subsection{Examination of Construct Validity}

Factor Analysis

Exploratory factor analysis was performed to examine the construct validity. First, the Kaiser-Meyer-Olkin (KMO) measure was 0.889 and a significant difference was found in the Bartlett's sphericity test. Factor analysis of the 80 items resulted in the adoption of a five-factor structure. Factor analysis was repeated until factor loading showed 0.4 or more for one factor and was not 0.4 or more for two factors. Finally, 44 items were chosen and the factorial validity was confirmed.

Factor 1 includes 19 items. This factor was named "Lack of triage ability". Factor 2 includes nine items. This factor was named "Busy triage work". Factor 3 includes six items. This factor was named "Patients without understanding of 
Table 1. Characteristics of study participants $(n=363)$.

\begin{tabular}{|c|c|c|c|}
\hline \multicolumn{2}{|c|}{ Characteristics } & Frequency & Percentage (\%) \\
\hline \multirow{2}{*}{ Gender $(n=363)$} & Female & 295 & 81.3 \\
\hline & Male & 68 & 18.7 \\
\hline \multirow{4}{*}{ Age (years) $(\mathrm{n}=363)$} & $20-29$ & 60 & 16.5 \\
\hline & $30-39$ & 167 & 46.0 \\
\hline & $40-49$ & 105 & 28.9 \\
\hline & $\geq 50$ & 31 & 8.5 \\
\hline \multirow{5}{*}{$\begin{array}{l}\text { Years of experience } \\
\text { as a nurse }(n=363)\end{array}$} & 3 & 9 & 2.5 \\
\hline & $3-5$ & 25 & 6.9 \\
\hline & $6-10$ & 94 & 25.9 \\
\hline & $11-15$ & 87 & 24.2 \\
\hline & $\geq 16$ & 148 & 40.8 \\
\hline \multirow{5}{*}{$\begin{array}{l}\text { Years of experience } \\
\text { in emergency care } \\
\qquad(\mathrm{n}=363)\end{array}$} & $<3$ & 45 & 12.4 \\
\hline & $3-5$ & 116 & 32.0 \\
\hline & $6-10$ & 131 & 36.1 \\
\hline & $11-15$ & 55 & 15.2 \\
\hline & $\geq 16$ & 16 & 4.4 \\
\hline \multirow{5}{*}{$\begin{array}{l}\text { Years of experience } \\
\text { as a triage nurse }(n=363)\end{array}$} & $<1$ & 64 & 17.6 \\
\hline & $1-3$ & 187 & 51.5 \\
\hline & $4-6$ & 92 & 25.3 \\
\hline & $7-9$ & 12 & 3.3 \\
\hline & $\geq 10$ & 8 & 2.2 \\
\hline \multirow{3}{*}{ Position $(n=363)$} & Head nurse & 15 & 4.1 \\
\hline & Chief (assistant head nurse) & 51 & 14.0 \\
\hline & Staff & 297 & 81.8 \\
\hline \multirow{3}{*}{ Certification $(n=363)$} & Certified nurse & 47 & 12.9 \\
\hline & Nurse specialist & 5 & 1.4 \\
\hline & None of the above & 311 & 85.7 \\
\hline \multirow{3}{*}{$\begin{array}{c}\text { Designation for } \\
\text { emergency and critical } \\
\text { care of hospital }(n=363)\end{array}$} & Tertiary care center & 190 & 52.3 \\
\hline & Secondary care center & 13 & 3.6 \\
\hline & Emergency and critical care center & 160 & 44.1 \\
\hline
\end{tabular}

explanation". Factor 4 includes six items. It was named "Complaints from patients waiting for treatment". Factor 5 includes four items. This factor was termed "Lack of support to improve triage ability".

Table 2 shows the results of the factor analysis. For the correlations of stressor factors, a moderate correlation was observed between Factor 3 and Factor 4 ( $r=$ $0.58 ; p<0.01)$. Moderate correlations were also indicated between Factor 2 and 
Table 2. Exploratory factor analysis of the TNJSS $(n=363)$ (44 items).

\begin{tabular}{|c|c|c|c|c|c|c|c|}
\hline & & Questionnaire item & F1 & F2 & F3 & F4 & F5 \\
\hline & 44 & Feel lack of assessment ability & 0.80 & 0.00 & -0.18 & 0.07 & -0.01 \\
\hline & 43 & Cannot determine the general condition & 0.78 & 0.08 & 0.13 & -0.15 & -0.06 \\
\hline & 38 & Forget what I should ask & 0.76 & 0.06 & -0.06 & -0.06 & -0.06 \\
\hline & 37 & Cannot conduct interview systematically & 0.76 & -0.05 & -0.08 & 0.11 & -0.07 \\
\hline & 36 & Cannot get any precise symptom information by interview & 0.72 & 0.02 & -0.06 & 0.09 & 0.01 \\
\hline & 42 & Overlooked somatoform symptoms & 0.72 & 0.07 & 0.19 & -0.11 & -0.08 \\
\hline & 46 & Cannot examine unfamiliar disease & 0.72 & -0.07 & -0.14 & 0.07 & 0.12 \\
\hline & 49 & Judged wrong triage level & 0.70 & 0.03 & 0.14 & -0.03 & -0.09 \\
\hline F1 & 41 & Cannot notice that patient's status deviated from normal & 0.69 & -0.01 & 0.13 & -0.05 & -0.09 \\
\hline Lack of & 28 & Difficult to predict disease & 0.67 & -0.10 & -0.06 & 0.06 & 0.01 \\
\hline triage abillty & 48 & Cannot understand clinical department that I have never experienced & 0.67 & -0.03 & -0.05 & -0.02 & 0.12 \\
\hline & 47 & There are unknown disease names and therapies & 0.66 & -0.16 & -0.11 & 0.15 & 0.03 \\
\hline & 45 & Can understand only emergency area & 0.65 & 0.01 & -0.04 & -0.12 & 0.13 \\
\hline & 50 & Diagnosis that I predicted was wrong & 0.65 & -0.02 & 0.19 & -0.11 & -0.02 \\
\hline & 40 & Feel the difference between physicians' and my interview skills & 0.63 & 0.16 & -0.14 & -0.06 & -0.07 \\
\hline & 26 & Cannot definitely judge the triage level & 0.61 & -0.03 & 0.01 & 0.09 & 0.09 \\
\hline & 35 & $\begin{array}{l}\text { Cannot understand all the symptoms because the patient complains of } \\
\text { many symptoms }\end{array}$ & 0.58 & 0.05 & 0.04 & 0.10 & -0.03 \\
\hline & 39 & Cannot stop patient's lengthy talk & 0.58 & 0.03 & 0.09 & 0.05 & 0.07 \\
\hline & 29 & Patient's symptoms are not typical & 0.51 & -0.04 & 0.00 & 0.08 & 0.04 \\
\hline & 86 & Accumulation of patients requiring triage & 0.03 & 0.78 & 0.00 & 0.07 & -0.06 \\
\hline & 83 & Many patients require a medical examination at the same time & -0.02 & 0.76 & -0.14 & 0.16 & 0.01 \\
\hline F2 & 84 & Patients overflow in a waiting room & -0.06 & 0.73 & 0.04 & 0.10 & -0.12 \\
\hline $\begin{array}{l}\text { Busy triage } \\
\text { work }\end{array}$ & 80 & Have to triage while assisting physicians who see and manage patients & 0.03 & 0.70 & -0.07 & -0.17 & 0.16 \\
\hline & 78 & Have to do both triage and other medical care & 0.06 & 0.69 & -0.10 & 0.01 & 0.01 \\
\hline & 85 & Several ambulances come in a day & -0.15 & 0.62 & 0.01 & 0.19 & -0.06 \\
\hline $\mathrm{F} 2$ & 87 & $\begin{array}{l}\text { Cannot record patient information immediately because there are } \\
\text { many triage tasks }\end{array}$ & 0.18 & 0.55 & 0.14 & -0.23 & 0.02 \\
\hline $\begin{array}{l}\text { Busy triage } \\
\text { work }\end{array}$ & 90 & There are too many patients to re-triage & 0.03 & 0.53 & 0.04 & 0.13 & 0.03 \\
\hline & 79 & Have to coordinate the entire emergency outpatient unit & -0.11 & 0.52 & 0.07 & -0.13 & 0.14 \\
\hline & 71 & Patients are drunk and cannot understand my explanation & -0.15 & 0.00 & 0.76 & -0.03 & -0.05 \\
\hline F3 & 66 & Patients have a panic attack & 0.10 & -0.07 & 0.75 & 0.06 & 0.02 \\
\hline $\begin{array}{l}\text { Patients } \\
\text { without }\end{array}$ & 62 & Receive verbal abuse from patients & -0.08 & -0.07 & 0.69 & 0.17 & 0.04 \\
\hline understanding & 61 & Receive violence from patients & -0.05 & 0.08 & 0.68 & -0.11 & 0.04 \\
\hline of explanation & 70 & Patients do not understand even if I repeat explanation & 0.14 & -0.04 & 0.64 & 0.10 & 0.04 \\
\hline & 68 & Exaggerate the explanation to convince patients & 0.03 & -0.02 & 0.56 & 0.11 & 0.02 \\
\hline
\end{tabular}




\section{Continued}

\begin{tabular}{|c|c|c|c|c|c|c|c|}
\hline & & Questionnaire item & F1 & F2 & F3 & F4 & F5 \\
\hline & 53 & Patients demand to be examined soon & 0.00 & -0.09 & -0.05 & 0.95 & 0.00 \\
\hline $\mathrm{F} 4$ & 57 & Patients repeatedly complain about long waiting times & -0.01 & 0.03 & 0.09 & 0.71 & 0.03 \\
\hline Complaints & 52 & Patients ask about the waiting time for medical examination & 0.07 & -0.02 & 0.00 & 0.68 & -0.04 \\
\hline waiting for & 54 & Patients claim that they want to lie down because they are tired & 0.02 & 0.14 & 0.07 & 0.61 & 0.03 \\
\hline treatment & 55 & Patients claim that they are in a most serious condition & 0.06 & 0.09 & 0.18 & 0.58 & -0.02 \\
\hline & 59 & Patients say that test results take too long & -0.03 & 0.06 & 0.29 & 0.45 & 0.03 \\
\hline F5 & 99 & There is no study session or workshop regarding triage & 0.03 & 0.01 & -0.15 & 0.11 & 0.82 \\
\hline $\begin{array}{l}\text { Lack of } \\
\text { support to }\end{array}$ & 96 & There is no verification of triage & -0.05 & 0.01 & 0.08 & -0.04 & 0.81 \\
\hline improve triage & 97 & There is no opportunity to reflect on triage cases & -0.02 & 0.02 & 0.11 & -0.02 & 0.79 \\
\hline ability & 100 & No one gives advice on triage & 0.06 & 0.09 & 0.04 & -0.05 & 0.67 \\
\hline Correlations o & f fact & & F1 & F2 & F3 & F4 & F5 \\
\hline & F1 La & $\mathrm{k}$ of triage ability & - & $0.17^{\star *}$ & $0.23^{* *}$ & $0.25^{\star *}$ & $0.30^{* *}$ \\
\hline & $\mathrm{F} 2 \mathrm{Br}$ & y triage work & & - & $0.33^{* *}$ & $0.33^{* *}$ & $0.17^{\star *}$ \\
\hline & F3 Pa & ients without understanding of explanation & & & - & $0.58^{\star *}$ & $0.14^{* *}$ \\
\hline & $\mathrm{F} 4 \mathrm{C}$ & mplaints from patients waiting for treatment & & & & - & $0.15^{* *}$ \\
\hline & F5 Pc & or support to improve triage ability & & & & & - \\
\hline
\end{tabular}

Factor sampling; principal factor method; rolling method; promax rotation, $\mathrm{F}=$ Factor, ${ }^{* *} p<0.01$, TNJSS $=$ Triage nurse job stressor scale.

Factor $3(r=0.33 ; p<0.01)$ and between Factor 2 and Factor $4(r=0.33 ; p<$ 0.01). For the other factors, weaker correlations were observed (Table 2).

\subsection{Known-Groups Analysis}

Known-groups analysis was performed to confirm the factors. First, Hypothesis 1 was examined. The nurses were classified into two groups according to years of emergency nursing experience: a less than 3 years group and a 3-year or more group. A Mann-Whitney $U$ test was conducted with the years of emergency nursing experience as an independent variable and stressor scores of triage nurses as a dependent variable. There were 45 nurses (12.4\%) in the less than 3 years group and 318 nurses (87.6\%) in the 3 years or more group. The results of the analysis demonstrated that the stressor scores of the less than 3 years group were significantly higher $(146.67 \pm 19.34)$ than those of the 3 years or more group $(138.81 \pm 21.29, p<0.05)$. Thus, nurses with less than three years' emergency nursing experience showed higher stressor scores than did nurses with three years or more. Therefore, Hypothesis 1 was supported.

Second, Hypothesis 2 was examined. The nurses were classified into two groups according to triage nurse experience: a less than 1 year group and a 1 year or more group. A Mann-Whitney $U$ test was conducted with years of triage nurse experience as a dependent variable and stressor scores of triage nurses as a dependent variable. There were 64 nurses (17.6\%) in the less than 1 year group 
and 299 nurses $(82.4 \%)$ in the 1 year or more group. The results of the analysis indicated that the stressor scores of the less than 1 year group were significantly higher $(144.93 \pm 18.33)$ than those of the 1 year or more group $(138.68 \pm 21.51 ; p$ $<0.05)$.

As nurses with less than one year experience as a triage nurse showed higher stressor scores than did nurses with one year or more, Hypothesis 2 was supported.

\subsection{Examination of Internal Consistency}

The Cronbach's $\alpha$ coefficients obtained for each subscale were 0.94 for Factor 1, Lack of triage ability; 0.87 for Factor 2, Busy triage work; 0.85 for Factor 3, Patients without understanding of explanation; 0.89 for Factor 4, Complaints from patients waiting for treatment; and 0.87 for Factor 5, Poor support to improve the triage ability. The $\alpha$ coefficient for the entire scale was 0.93 .

\subsection{Examination of Internal Consistency}

To determine criterion-related validity, convergent validity was examined. A correlation between TNJSS scores and SRS-18 total scores was observed $(r=$ $0.41, p<0.01)$. For correlations between the stressor scale total scores and the SRS-18 subscale scores, significant correlations were observed for depression-anxiety $(r=0.39, p<0.01)$, displeasure-anger $(r=0.34 ; p<0.01)$, and apathy $(r=0.42, p<0.01)$ (Table 3$)$.

A correlation with the NJSS total scores was also observed $(r=0.41, p<0.01)$. Associations were indicated between the stressor scale total scores and all of the NJSS subscale scores: significant correlations were observed for conflict with other nursing staff $(r=0.29, p<0.01)$, conflict from the role as a nursing professional $(r=0.33, p<0.01)$, conflict with physicians or autonomy as a nursing professional $(r=0.31, p<0.01)$, conflict with death $(r=0.33, p<0.01)$, qualitative

Table 3. Correlations between TNJSS scores and SRC-18 scores $(\mathrm{n}=363)$.

\begin{tabular}{|c|c|c|c|c|c|c|c|}
\hline & & \multicolumn{6}{|c|}{ TNJSS } \\
\hline & & \multirow[b]{2}{*}{$\begin{array}{l}\text { Total } \\
\text { score }\end{array}$} & F1 & F2 & F3 & F4 & F5 \\
\hline & & & $\begin{array}{c}\text { Lack of } \\
\text { triage ability }\end{array}$ & $\begin{array}{l}\text { Busy triage } \\
\text { work }\end{array}$ & $\begin{array}{l}\text { Patients without } \\
\text { understanding of } \\
\text { explanation }\end{array}$ & $\begin{array}{l}\text { Complaints from } \\
\text { patients waiting for } \\
\text { treatment }\end{array}$ & $\begin{array}{l}\text { Lack of support } \\
\text { to improve } \\
\text { triage ability }\end{array}$ \\
\hline \multirow{4}{*}{ SRS -18} & Total score & $0.41^{\star *}$ & $0.38^{* *}$ & $0.28^{* *}$ & $0.20^{* *}$ & $0.23^{* *}$ & $0.18^{\star *}$ \\
\hline & $\begin{array}{l}\text { F1 } \\
\text { Depression-anxiety }\end{array}$ & $0.39^{* *}$ & $0.38^{* *}$ & $0.23^{* *}$ & $0.23^{* *}$ & $0.23^{* *}$ & $0.17^{\star *}$ \\
\hline & $\begin{array}{l}\text { F2 } \\
\text { Displeasure-anger }\end{array}$ & $0.34^{* *}$ & $0.25^{\star *}$ & $0.27^{\star *}$ & $0.20^{* *}$ & $0.25^{* *}$ & $0.12^{*}$ \\
\hline & $\begin{array}{l}\text { F3 } \\
\text { Apathy }\end{array}$ & $0.42^{\star *}$ & $0.45^{\star *}$ & $0.26^{* *}$ & $0.13^{*}$ & $0.14^{* *}$ & $0.22^{\star \star}$ \\
\hline
\end{tabular}

Spearman correlation coefficient; ${ }^{* *} p<0.01 ;{ }^{*} p<0.05, \mathrm{~F}=$ Factor, SRS-18 $=$ stress reaction scale-18 (Suzuki et al., 2004), TNJSS $=$ triage nurse job stressor scale. 
Table 4. Correlations between TNJSS scores and NJSS scores $(\mathrm{n}=363)$.

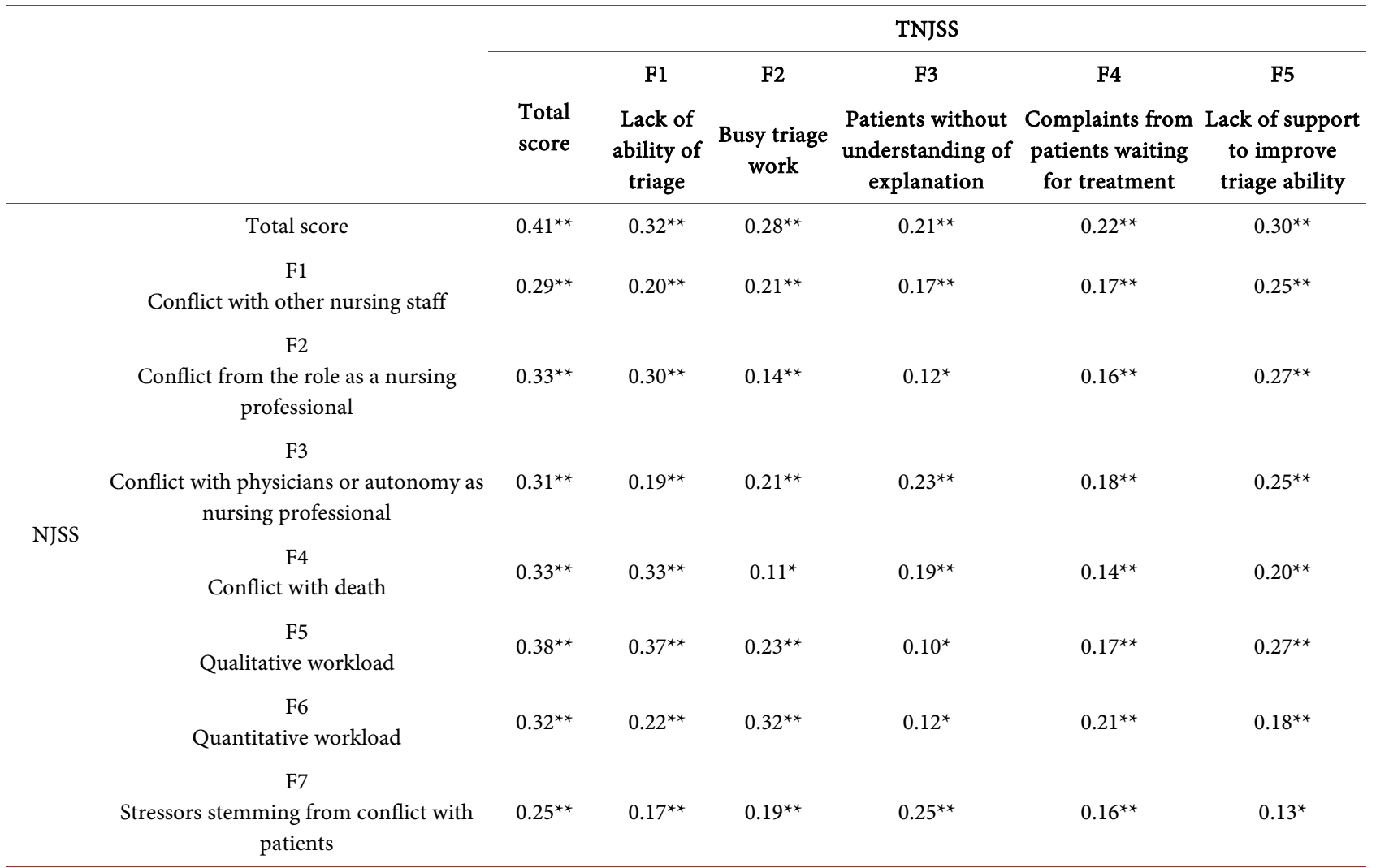

Spearman coefficient of correlation; ${ }^{* *} p<0.01 ;{ }^{*} p<0.05, \mathrm{~F}=$ Factor, NJSS $=$ Nursing job stressor scale (Higashiguchi et al., 1998$)$, TNJSS $=$ Triage nurse job stressor scale.

workload ( $r=0.38, p<0.01)$, quantitative workload $(r=0.25, p<0.01)$, and for stressors stemming from conflict with patients $(r=0.25, p<0.01)$ (Table 4$)$.

\section{Discussion}

\subsection{Extraction of Job Stressors}

On examination on the job stressors experienced by Japanese triage nurses the following 5 factors were extracted: "Lack of triage ability", "Busy triage work", "Patients without understanding of explanation", "Complaints from patients waiting for treatment", and "Lack of support to improve triage ability". On comparison of the 5 factors of the TNJSS with the 7 factors of the commonly used NJSS (i.e., "Conflict with other nursing staff", "Conflict from the role as a nursing professional", "Conflict with physicians or autonomy as nursing professional", "Conflict with death", "Quantitative work load", "Qualitative work load", and "Conflict with patients"), it becomes clear that triage nurses experience specific stressors not commonly encountered by the conventional nursing population, such as "Lack of triage ability" and "Lack of support to improve triage ability". In particular, "Lack of triage ability", which includes as many as 19 subcategories, seems to weigh heavily on triage nurses' stress in Japan. As this stressor cannot be accounted for by using the NJSS, the impact the TNJSS will 
have on the improved measurement of triage nurses' stress levels is easily understood. Further, "Lack of triage ability" might not be unique to the Japanese situation but also reasonably encountered in other countries, hence an impact of the TNJSS on the international stage is indicated.

\subsection{Reliability of the TNJSS}

Cronbach's $\alpha$ coefficients, derived to examine the internal consistency of the constituted scales, was 0.93 for all the items and 0.85 or higher for each sub-factor. Considering that the Cronbach coefficient should be $>0.6$ to ensure sufficient internal consistency [25], the TNJSS was considered to have a good internal consistency.

\subsection{Validity of the TNJSS}

The scale's item selection and item wording were examined thoroughly by a panel of nursing researchers and nurses who were familiar with emergency nursing. Therefore, the contents of the stressor items and the naming of the subscales were considered appropriate. The five factors extracted by factor analysis in the present study were almost identical with the stressors extracted previously by Nojima. Therefore, the content validity of the stressor scale was established.

In addition, in the known-group analysis, statistical testing was conducted with the participants' characteristics and the TNJSS stressor scores in order to examine Hypothesis 1, "Nurses with less than three years' emergency nursing experience show higher stressor scores than do nurses with three years or more of experience." and Hypothesis 2 "Nurses with less than one year triage nursing experience show higher stressor scores than do nurses with one year or more of experience." As a result, both Hypothesis 1 and Hypothesis 2 were supported ( $p$ $<0.05$; Mann-Whitney-U test). According to the above results, construct validity was established.

Since the present scale is intended to measure stressors of triage nurses, its correlations with the SRS-18 scale and the NJSS were examined to verify convergent validity. The results of the analysis demonstrated that the level of correlation between the stressor scores of the TNJSS and the total SRS-18 scores was medium $(r=0.41 ; p<0.01)$ and medium to weak with each factor (F1: $r=0.25$ $0.45, p<0.01$; F2: $r=0.23-0.28, p<0.01$; F3: $r=0.13-0.23, p<0.01$; F4: $r=$ $0.14-0.25, p<0.01$; and F5: $r=0.12-0.18, p<0.01$ ). The level of correlation of the TNJSS with the total NJSS scores was also medium $(r=0.41 ; p<0.01)$ and medium to weak with each factor (F1: $r=0.17-0.37, p<0.01 ; \mathrm{F} 2: r=0.11-0.32$, $p<0.01$; F3: $r=0.10-0.25, p<0.01$; F4: $r=0.14-0.21, p<0.01$; and F5: $r=0.13$ $-0.27, p<0.01)$. Together, these results indicate that the TNJSS can measure the job stressors of triage nurses appropriately and satisfactorily.

\subsection{Novelty and Contributions of This Study}

Triage nurses are known to be subject to various stressors, and this has been re- 
garded as a serious issue in Japan. However, there has been no scale to measure the feelings of stress of this population quantitatively, and there have been no adequate measures taken to alleviate stressors that are present. The novelty of the present study is that it developed a triage nurse job stressor scale (TNJSS) for triage nurses in emergency outpatient units and verified the validity and reliability of the scale. With this scale, it will be possible to consider and establish support for triage nurses to alleviate the stressors, something which was previously insufficiently attempted, and the scale has the potential to contribute to the quality and other aspects of emergency nursing.

\subsection{Study Limitations and Future Considerations}

The present study represents the first report on the development of a job stressor scale for triage nurses. Hence, the present version of the TNJSS is to be considered as the base on which to develop it further. In particular, the current subfactor structure will need further refinement, as factor 1 contains 19 items while the other 4 factors contain only 4 - 9 items. In the present study we sent out anonymous, voluntary, self-administered questionnaires across Japan after random selection of 180 medical institutions as the target. By nature of this sampling method, there is a possibility that the data contain a selection bias, so it will be necessary to repeatedly cross-validate the TNJSS in various target populations with regard to geographic region, size of the medical institution, and triage nurses' characteristics.

Two of the stressor factors extracted by the present research related to triage ability, namely factor 1 "Lack of triage ability" and factor 5 "Lack of support to improve triage ability". These results point to the immediate need to establish a system to systematically educate and train triage nurses as well as to build support measures to improve and maintain the professional level and the confidence of triage nurses in Japan.

\section{Conclusion}

The TNJSS has sufficient reliability and validity as a five-factor structure containing 44 items, and is a valid tool for evaluating Japanese triage nurse job stressors. In addition, the data indicate the immediate need to establish a system to continuously educate and support triage nurses. The TNJSS has sufficient reliability and validity as a five-factor structure containing 44 items, and is a valid tool for evaluating Japanese triage nurse job stressors. In addition, the data indicate the immediate need to establish a system to continuously educate and support triage nurses.

\section{Acknowledgements}

We greatly thank the triage nurses who participated in this study. This study was supported by a JSPS KAKENHI Grant-in-Aid for Young Scientists (B; No. $15 \mathrm{~K} 2072$ ). Part of this study was presented at the $36^{\text {th }}$ conference of the Japan 
Academy of Nursing Science.

\section{Conflicts of Interest}

The authors declare no conflicts of interest regarding the publication of this paper.

\section{References}

[1] Cañadas-De la Fuente, G.A., Vargas, C., San Luis, C., García, I., Cañadas, G.R. and De la Fuente, E.I. (2015) Risk Factors and Prevalence of Burnout Syndrome in the Nursing Profession. International Journal of Nursing Studies, 52, 240-249. https://doi.org/10.1016/j.ijnurstu.2014.07.001

[2] da Silva, J.L., Soares Rda, S., Costa Fdos, S., Ramos Dde, S., Lima, F.B. and Teixeira, R.L. (2015) Psychosocial Factors and Prevalence of Burnout Syndrome among Nursing Workers in Intensive Care Units. Revista Brasileira de Terapia Intensiva, 27, 125-133. http://dx.doi.org/10.5935/0103-507X.20150023

[3] Goodfellow, A., Varnam, R., Rees, D. and Shelly, M.P. (1997) Staff Stress on the Intensive Care Unit: A Comparison of Doctors and Nurses. Anaesthesia, 52, 1037-1041. https://doi.org/10.1111/j.1365-2044.1997.213-az0348.x

[4] Kant, S., Murmu, L.R. and Kumar, A. (1995) Level of Stress among Medical and Nursing Personnel Working in the Emergency Department of a Teaching Hospital. Journal of Hospital Administration, 7, 13-18.

[5] Ribeiro, V.F., Filho, C.F., Valenti, V.E., Ferreira, M., Abreu, L.C., Carvaiho, T.D., et al. (2014) Prevalence of Burnout Syndrome in Clinical Nurses at a Hospital of Excellence. International Archives of Medicine, 7, 22.

[6] Elder, R., Neal, C., Davis, B.A., Alems, E., Whiteledge, L. and Littlepage, N. (2004) Patient Satisfaction with Triage Nursing in a Rural Hospital Emergency Department. Journal of Nursing Care Quality, 19, 263-268. https://doi.org/10.1097/00001786-200407000-00013

[7] Hamamoto, J., Yamase, H. and Yamase, Y. (2014) Impacts of the Introduction of a Triage System in Japan: A Time Series Study. International Emergency Nursing, 22, 153-158. https://doi.org/10.1016/j.ienj.2013.10.006

[8] Bailey, A., Hallam, K. and Hurst, K. (1987) Nursing Practice. Triage on Trial. Nursing Times, 83, 65-66.

[9] Stover-Baker, B., Stahlman, B. and Pollack, M. (2012) Triage Nurse Prediction of Hospital Admission. Journal of Emergency Nursing, 38, 306-310. https://doi.org/10.1016/j.jen.2011.10.003

[10] Watanabe, Y. (2011) Ability Deemed Necessary for Triage Nurses. Nursing Today, 26, $18-20$

[11] Yamase, H. (2002) Actual Situation of Stress of Nurses in Emergency Care. Emergency Nursing, 15, 16-21.

[12] Nojima, K. (2016) Stressor of Triage Nurses in Emergency outpatient Unit: Contents of Stressor Regarding Their Role and Ability. Journal of the Japanese Association for Emergency Nursing, 18, 11-18.

[13] Kubo, M. and Tao, M. (1994) Burnout among Nurses: The Relationship between Stresses and Burnout. The Japanese Journal of Experimental Social Psychology, 34, 33-43. https://doi.org/10.2130/jjesp.34.33

[14] Hinds, P.S., Fairclough, D.C., Dobos, C.L., Greer, R.H., Herring, P.L., Mayhall, J., et 
al. (1990) Development and Testing of the Stressor Scale for Pediatric Oncology

Nurses. Cancer Nursing, 13, 354-360.

https://doi.org/10.1097/00002820-199012000-00005

[15] Matsumoto, K., Sumino, K., Fukahori, H., Kitaoka, K., Kamibeppu, K. and Nagamura, F. (2012) Stressor Scale for Clinical Research Coordinators: Development and Psychometric Testing. Journal of Advanced Nursing, 68, 1636-1645. https://doi.org/10.1111/j.1365-2648.2012.05972.x

[16] Yada, H., Abe, H., Funakoshi, Y., Omori, H., Matsuo, H., Ishida, Y., et al. (2011) Development of the Psychiatric Nurse Job Stressor Scale (PNJSS). Psychiatry and Clinical Neurosciences, 65, 567-575. https://doi.org/10.1111/j.1440-1819.2011.02258.x

[17] Fujiwara, C., Honda, I., Hoshi, K., Ishida, Y., Ishii, K. and Hinokuma, F. (2001) Study on Job Stress of Inexperienced Nurses: Development of Job Stressor Scale and Analysis of Influence Factors. Journal of the Japanese Society of Nursing Research, 24, 77-88.

[18] Higashiguchi, K., Morikawa, Y., Miura, K., Nshijo, M., Tabata, M. and Nakagawa, H. (1998) Work Stressors of Clinical Nursing Professionals: Development of Work Stressor Measure and Examination of Psychological Assumption Characteristics. The Japanese Journal of Health Psychology, 11, 64-72.

https://doi.org/10.11560/jahp.11.1_64

[19] Ando, Y., Kataoka, T., Okamura, H., Tanaka, K. and Kobayashi, T. (2013) Development of a Job Stressor Scale for Nurses Caring for Patients with Intractable Neurological Diseases. Hiroshima Journal of Medical Sciences, 62, 69-76.

[20] Kikuchi, C., Tsuji, M. and Yamaguchi, J. (2008) Stress Factual Survey in Nurses Working in Outpatient Unit Using Work Stressor Measure for Clinical Nursing Professionals. Journal of Farm Village Medical Society in Four Prefectures in Tokai, 34, 32-35.

[21] Manabe, E., Komatsu, M. and Okayama, Y. (2014) A Study on Job Stressors and Stress Response in Inexperienced Nurses When They Worked from the First Year to the Third Year: Analysis by a Longitudinal Study in Nurses after Graduation from Bachelor of Nursing Program. Journal of the Japanese Society of Nursing Research, 37, 123-231.

[22] Shimajiri, F., Okamoto, K., Nishimura, A., Imado, S., Sawai, K. and Saito, I. (2013) An Analysis of Questionnaire Results to Improve the Quality of Triage in an Emergency Outpatient Unit. Journal of the Japanese Society for Emergency Medicine, 16, 802-809.

[23] Suzuki, A., Toyoda, H. and Kosugi, S. (2004) Construction of a Stress Reaction Scale Based on an Item Response Model and Examination of the Developmental Process of Psychological Stress Reactions by Using Test Characteristic Curves. The Japanese Journal of Psychology, 75, 389-396. https://doi.org/10.4992/jjpsy.75.389

[24] Maki, S., Sasagawa, M. and Hitotsune, H. (2007) Actual Situation and Related Factors of Traumatic Stress and Mental Health of Nurses Engaging in Tertiary Care. Journal of the Japanese Association for Emergency Nursing, 8, 43-52.

[25] George, D. and Mallery, P. (2002) SPSS for Windows Step by Step: A Simple Guide and Reference, 11.0 Update. 4th Edition, Allyn \& Bacon, Boston. 